\title{
A unique case of recurrent uterine inversion requiring double reposition
}

\author{
Nirmala Sharma ${ }^{1}$, Kana $\operatorname{Ram}^{1}$, Anand Sharma ${ }^{2}$, Shashi Sharma ${ }^{1}$ \\ ${ }^{1}$ Department of Obstetrics \& Gynaecology, Govt. Medical College, Kota, Rajasthan, India \\ ${ }^{2}$ Department of Medicine, Govt. Medical College, Kota, Rajasthan, India
}

Received: 26 April 2013

Accepted: 10 May 2013

*Correspondence:

Dr. Nirmala Sharma,

E-mail: nirmala_gynae@yahoo.co.in

(C) 2013 Sharma $\mathrm{N}$ et al. This is an open-access article distributed under the terms of the Creative Commons Attribution Non-Commercial License, which permits unrestricted non-commercial use, distribution, and reproduction in any medium, provided the original work is properly cited.

\begin{abstract}
Acute puerperal uterine inversion is a rare but life threatening complication of third stage of labour. The incidence varies widely between 1 in 2000 to 1 in 50,000 deliveries, largely dependent upon the standard of management of the third stage of labour. Acute uterine inversion occurs within 24 hours delivery; subacute between 24 hours and 4 weeks of delivery and chronic uterine inversion after 4 weeks or in the non pregnant state. Cases of subacute and chronic uterine inversion require surgical management.
\end{abstract}

Keywords: Primipara, Uterine inversion, Postpartum hemorrhage

\section{INTRODUCTION}

Uterine inversion occurs when the uterine fundus collapses into the endometrial cavity, turning the uterus partially or completely inside out. It is a rare complication of vaginal or cesarean delivery, but when it occurs, it is a life-threatening obstetrical emergency. If not promptly recognized and treated, uterine inversion can lead to severe hemorrhage and shock, resulting in maternal death.

Uterine inversions are classified by the extent of inversion and time of occurrence:

\section{Extent of inversion}

- $\quad 1^{\text {st }}$ degree (incomplete) inversion: the fundus is within the endometrial cavity.

- $2^{\text {nd }}$ degree (complete) inversion: the fundus protrudes through the cervical os.

- $3^{\text {rd }}$ degree inversion (uterine prolapse): the fundus protrudes to or beyond the introitus.
- $4^{\text {th }}$ degree (total uterine and vaginal) inversion: both the uterus and vagina are inverted.

\section{CASE REPORT}

A 21-year old primipara was referred to our hospital on 19.1 .13 as a case of post partum hemorrhage. She had a vaginal delivery, 8 hours prior in a peripheral hospital and had given birth to a healthy male baby, weighing $2.5 \mathrm{~kg}$. On arrival to our hospital, the patient was extremely pale with bleeding per vaginum, her pulse rate was $94 \mathrm{bpm}$, her BP was 100/60 mm $\mathrm{Hg}$ and uterus was 16-18 weeks size, initially in emergency room it was diagnosed as a case of PPH by casualty medical officer and patient was treated on line of $\mathrm{PPH}$ and after removing clots from vagina, her bleeding per vaginum ceased but BP was falling detrimentally and reached $70 / 50 \mathrm{~mm} \mathrm{Hg}$ and casualty medical officer was unable to manage the patient so consultant was called to examine the patient and per vaginum examination was performed again by consultant which revealed a fleshy mass (inverted uterus) and a final diagnosis of acute uterine inversion with neurogenic 
shock is made. Antishock measures, antibiotic therapy were instituted and two units of packed cell volume were transfused.

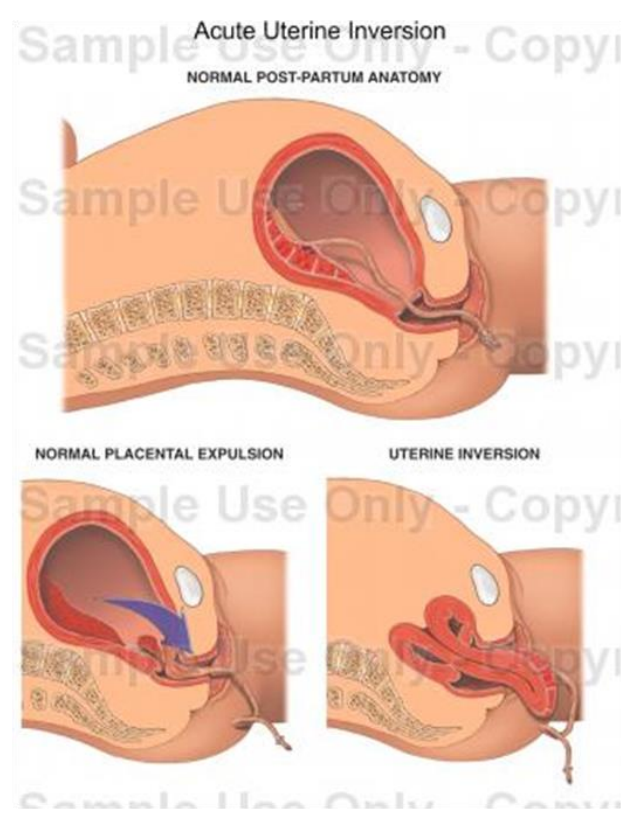

Figure 1: Depicting normal post partum anatomy and inversion of uterus.

Manual reposition was performed under controlled general anesthesia followed by uterine packing. Patient's condition improved but when packing was removed uterus again started inverting slowly and USG revealed incomplete inversion with fundus reaching upto internal os.

Laparotomy was decided, thorough vaginal douching was done and on laparotomy, the cup of the uterine inversion was identified (Figure 3).

Posterior constriction ring was cut and traction on the round ligaments was given, as the fundus of the uterus was pushed from vagina and the reposition was successful inspite of oedema, ischemia with the vaginal surgeon attempting to reduce the uppermost part of inverted uterus, first on one side and then on the other side. The uterus was pale and flabby with some ischemic areas, oxytocics were given to aid tonicity and to prevent reinversion packing was also done. The patient was observed in the high definition unit for 24 hours, two units of whole blood transfused, higher antibiotics and oxytocin patency drip were administered. Packing was removed after 24 hours, there was no bleeding per vaginum and patient was stable. USG get done again in fear of recurrence of inversion which revealed normal study. Patient was discharged after 7 days of observation and post operative care. This case is unusual in the sense that it recurred after 24 hours of manual reposition and was recorrected at laparotomy.
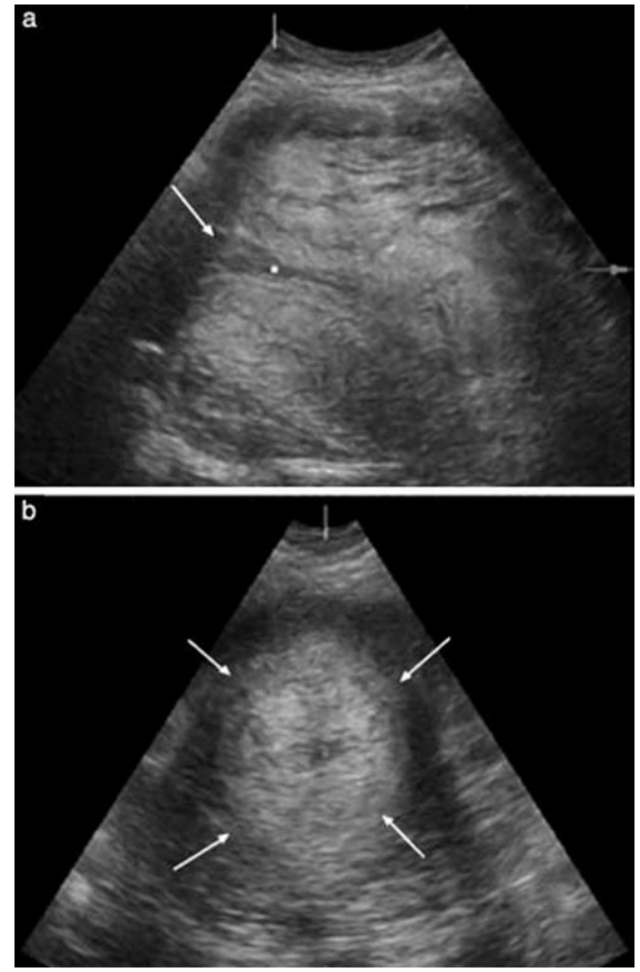

Figure 2: USG images of the uterus: (a) In the sagittal plane showing the inverted fundus as a central craterlike depression (arrow) and (b) In the axial plane showing the constriction ring (arrows).

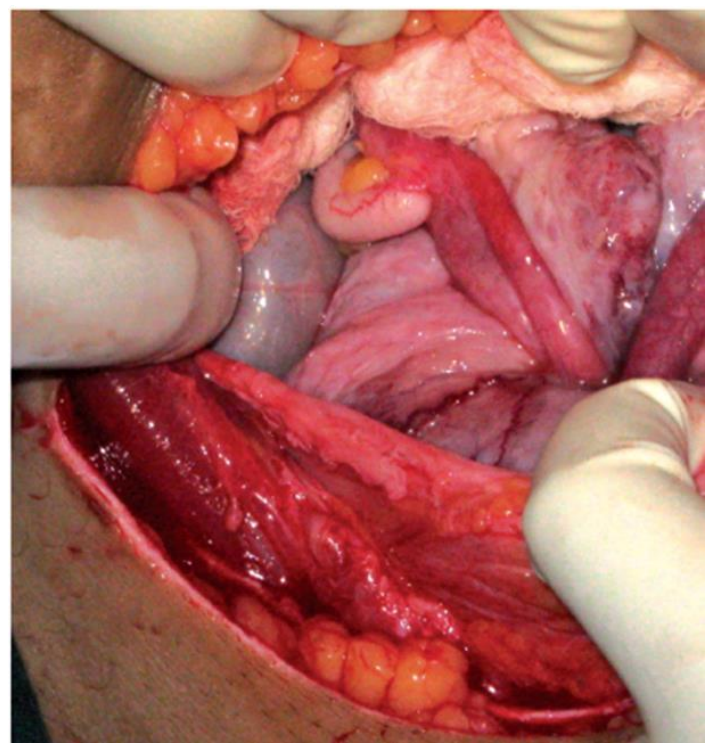

Figure 3: Cup of uterine inversion seen on laparotomy.

\section{DISCUSSION}

The exact etiology of uterine inversion remains unclear, but the most common and likely cause is mismanagement of the third stage of labour. The incidence of uterine inversion is 1 in 8537 (India), 1 in 23127 (US) and 1 in 27902 (Britain). ${ }^{1}$ The risk factors for spontaneous uterine 
inversion are primiparity, oxytocin use, the fundal insertion of the placenta, a short umbilical cord, macrosomia and uterine abnormality. The most common clinical presentation is pain, vaginal bleeding and shock. The treatment requires the immediate implementation of shock therapy, uterine repositioning and antibiotic therapy. The nonsurgical methods are manual repositioning (Johnson's maneuver) and hydrostatic reduction (O'Sullivan). The surgical methods include the incision of the constriction ring vaginally (Spinelli), upward traction on the round ligaments with the assistant applying upward pressure from the vagina (Huntington) and incising the constriction ring posteriorly at laparotomy (Haultain). The newer methods include laparoscopic reduction ${ }^{2}$, the use of obstetric ventouse at laparotomy ${ }^{3}$, and application of cephalad traction on the deepest visible part of the posterior uterus ${ }^{4}$.

\section{CONCLUSION}

Laparotomy helped us to achieve successful repositioning, and we saved her life and preserved her uterus for future pregnancies as she was a primipara.

\section{REFERENCES}

1. Van Vugt PJH, Baudoin P, Blom MV, van Deursen STBM. Inveriso uteri puerperalis. Acta Obstet Gynaecol Scand 1981;60:353-62.

2. Rajagopalan V, Sujatha Y. Acute postpartum uterine inversion with hemorrhagic shock with laparoscopic reduction: a new method of management. BJOG 2006;113:1100-2.

3. Antonelli E, Irion O, Tolck P, Morales M. Subacute uterine inversion: description of a novel replacement technique using the obstetric ventouse. BJOG 2006;113:846-7.

4. Robson S, Adair S, Bland P. A new surgical technique for dealing with uterine inversion. Australian and New Zealand Journal of Obstetrics and Gynaecology 2005;45:248-58.

5. Pauleta JR, Rodrigues R, Melo MA, Graça LM. Ultrasonographic diagnosis of incomplete uterine inversion. Ultrasound Obstet Gynecol 2010;36:260.

DOI: 10.5455/2320-1770.ijrcog20130935

Cite this article as: Sharma N, Ram K, Sharma A, Sharma S. A unique case of recurrent uterine inversion requiring double reposition. Int J Reprod Contracept Obstet Gynecol 2013;2:427-9. 